\title{
INTERNAL, MOLECULAR, OR INTRINSIC PRESSURE-A SURVEY OF THE VARIOUS EXPRESSIONS PROPOSED FOR ITS DETERMINATION.
}

\author{
By Wm. C. McC. LEWIS, M.A., D.Sc., Physical Chemistry Laboratory, \\ University College, London.
}

(A Paper read before the Faraday Society, Tuesday, May 2, I9II, Mr. James Swinburne, F.R.S., President, in the Chair.)

Thomas Young* in 1805 was the first to suggest that the phenomenon of surface tension was to be attributed to the mutual attraction of the parts of the liquid, acting through a very small range, these same forces giving rise to the phenomenon of cohesion in liquids and solids. Along with these cohesive forces we have likewise to postulate repulsive forces in operation, the distribution of the material in space being determined by the relative effects of these opposing agencies. Laplace, whose name is generally quoted as the originator of these ideas, was the first to give them mathematical expression. The cohesive force per unit area, or pull per square $\mathrm{cm}$., between two semiinfinite masses denoted by $\mathrm{K}$ was shown by Laplace to be expressible as the product of two terms-one a density term, the other an integral, thus-

$$
\mathrm{K}=\delta^{2} \int_{0}^{e=\bar{\infty}} \psi(z) d z
$$

The upper limit of the integral denotes that value of $z$ for which $\psi(z)$ vanishes. This limit $c$ is called the range of molecular action.

It must be remembered that Laplace took a static and not a dynamic view of the constitution of matter. On such a view the idea of repulsive forces is rather an artificial one, being simply introduced because something of the kind is necessary. On the kinetic view, however, the supposition of such opposing effects becomes at least a reasonable one. Calling $p$ the vapour pressure of the liquid, $\theta$ the thermal pressure, i.e., the effective pressure, of the nature of a repulsion having its origin in the kinetic energy of the molecules, these being regarded as distributing themselves in space at an average distance apart as the result of continuously recurring collisions, equilibrium ("temperature equilibrium") is established, when we have the relation-

$$
p+\mathrm{K}=\theta \text {. }
$$

Now since $p$ is very small compared to $\mathrm{K}$ for liquids and solids, we can write with very great accuracy indeed-

$$
\mathrm{K}=\theta \text {. }
$$

It is therefore immaterial, so far as numerical values are concerned, whether we fix our attention on the internal pressure or on the thermal pressure, which acts in the opposite sense. Having defined the term internal,

* Cf. Lord Rayleigh, Phil. Mag., 30, 285-298, 456-475, I89o. Likewise Scientific Papers, vol. iii., p. 397 . 
or, as it is sometimes called, molecular or intrinsic (Rayleigh) pressure, we may proceed to consider the attempts which have been made from time to time to give it numerical expression.

\section{Thomas Young's Estimate of the Internal Pressure of Liquid Water.}

The values which one obtains of the tensile strength of solids (say in the form of wire) give a measure-or at least mark an inferior limit-of the cohesive forces existing in such bodies; so that Young, in determining his moduli of elasticity, was in a position to gain some idea of the magnitude of $\mathrm{K}$ in these cases. Young's estimate of the internal pressure of water is 23,000 atmospheres. With regard to it Rayleigh (loc. cit.) says, "It is not clear upon what basis he proceeded, but a chance remark suggests that it may have bcen upon the assumption that cohesion was of the same order of magnitude in liquids and solids. Against this it may be objected that the estimate is unduly high. Even steel is scarcely capable of withstanding a tension of 23,000 atmospheres."

\section{Duprés Formula.}

In 1865 in the Annales de Chimie et de Physique, 6, 283, and later in the Théorie Mécanique de la Chaleur, Paris, 1869, A. Dupré suggested a rather novel method of obtaining values for $\mathrm{K}$. It was based on considerations of energy which involve the first law of thermodynamics but not the second. It is evident that $\mathrm{K}$ may be taken as numerically identical with the internal work done per unit volume of liquid against the molecular attractive forces when the molecules are supposed to have been pulled apart outside the range of their mutual action. Now relatively to a liquid we may regard a vapour as approximately representing a state in which the molecules are outside the limiting range referred to. Of course this is not strictly true (as otherwise there would be no necessity for an equation such as that of van der Waals to be applied to vapours), but it is safe to assume that the value of $\mathrm{K}$ in the vapour state is extremely small compared to its value for the same substance in the liquid form at ordinary temperatures. Hence the internal work done in vaporising unit volume of a liquid, that is to say, $\mathrm{K}$, should be identical with the internal latent heat of vaporisation per unit volume-call it $\mathrm{L}_{i}$ - provided molecular forces do not alter with temperature. What Dupré really did was to equate internal energy to an internal work term, his relation being expressed-

$$
\mathrm{K}=\mathrm{L}_{i}=\frac{\lambda_{i}}{v}
$$

where $\lambda_{i}$ refers to one gram and $v$ is the specific volume.

Applying this relation to the case of water, for example, at ordinary temperature, the internal latent heat per gram is 570 cals. This may also be taken as referring to unit volume. Hence-

$$
\begin{aligned}
\mathrm{K}_{\mathrm{H}_{2} \mathrm{O}} & =570 \times 4.2 \times 10^{7} \text { ergs per c.c. or dynes per cm. }{ }^{2} . \\
& =23,900 \mathrm{~atm} . / \mathrm{sq} . \mathrm{cm} .
\end{aligned}
$$

It will be observed how extraordinarily close Young's estimate is to this. In the case of ethyl ether, proceeding in the same way, we obtain-

For ethyl alcohol-

For carbon bisulphide-

$$
\mathrm{K}_{\left(\mathrm{C}_{2} \mathrm{H}_{5}\right)_{2} \mathrm{O}}=2,426 \mathrm{~atm} \text {. }
$$

$$
\mathrm{K}_{\mathrm{C}_{2} \mathrm{H}_{5} \mathrm{OH}}=7,266 \mathrm{~atm} \text {. }
$$

$$
\mathrm{K}_{\mathrm{CS}_{2}}=4,704 \mathrm{~atm} \text {. }
$$




\section{6}

INTERNAL, MOLECULAR, OR INTRINSIC PRESSURE

These values are no doubt of the correct order of magnitude-and it will be seen that we are dealing with extraordinarily large quantities-but more than this cannot be said. On introducing the principle of the second law of thermodynamics into Duprés considerations, it seems reasonable to expect a relation of the ordinary form -

$$
\mathrm{K}-\mathrm{L}_{i}=\mathrm{T}\left(\frac{\partial \mathrm{K}}{\partial \mathrm{T}}\right)_{v}
$$

or-

$$
\mathrm{L}_{i}=-\mathrm{T}^{2} \frac{\partial}{\partial \mathrm{T}}\left(\frac{\mathrm{K}}{\mathrm{T}}\right)
$$

It must be remembered, however, that thermodynamic work terms are essentially external work terms. The relation of $\mathrm{K}$ to $\mathrm{L}_{i}$ appears, however, to be analogous to the relation of $\mathrm{A}$ to $\mathrm{Q}$ in ordinary cases.

To evaluate this we must know something about the variation of $\mathrm{K}$ with $\mathrm{T}$, and so far this has not been possible.

Dupré * had already suggested another important relationship, which may be most conveniently put in the form-

where-

$$
\mathrm{K}=-\mathrm{T} \frac{a_{\mathrm{x}}}{\beta}
$$

$\boldsymbol{a}_{\mathrm{r}}=$ coefficient of expansion of the liquid with temperature,

$\beta=$ coefficient of compressibility of the liquid at constant temperature,

$\mathrm{T}=$ absolute temperature.

This relation may be obtained in a different manner to that of Dupre by applying an equation of the van der Waals type, viz.-

$$
p=\frac{\mathrm{RT}}{v-b}-\mathrm{K}
$$

On differentiating with respect to T, and assuming, as Dupré did, that $K$ is. independent of temperature, we obtain-

$$
\left(\frac{\partial p}{\partial T}\right)_{v}=\frac{p+K}{T}=\frac{K}{T}
$$

neglecting $p$ compared to $\mathrm{K}$.

Now bringing in the well-known thermodynamic relation, viz.-

$$
\left(\frac{\partial v}{\partial \mathrm{T}}\right)\left(\frac{\partial \mathrm{T}}{\partial p}\right)_{v}\left(\frac{\partial p}{\partial v}\right)_{\mathrm{T}}=-\mathrm{I}
$$

which holds for any system, we find-

$$
\mathrm{K}=-\mathrm{T}\left(\frac{\partial v}{\partial \mathrm{T}}\right)_{p}\left(\frac{\partial p}{\partial v}\right)_{\mathrm{T}}=-\frac{\frac{\mathrm{T}}{v}\left(\frac{\partial v}{\partial \mathrm{T}}\right)_{p}}{\frac{\mathrm{T}}{v}\left(\frac{\partial v}{\partial p}\right)_{\mathrm{T}}}=-\mathrm{T} \frac{\alpha_{\mathrm{x}}}{\beta}
$$

Dupré gives a table of results obtained by using this formula. $\dagger$ The

* Ann. de Chim. et de Phys. 2, 201, 1864.

+ Ibid., 2, 204, 1864. 
values are for $0^{\circ} \mathrm{C}$. except in the case of water, which is at $100^{\circ} \mathrm{C}$. (One obviously obtains negative values for $\mathrm{K}$ on applying the above formula to the case of water at $0^{\circ} \mathrm{C}$. and zero values at $4^{\circ} \mathrm{C}$.)

\begin{tabular}{|c|c|c|c|c|c|c|}
\hline \multicolumn{3}{|l|}{ Substance. } & $\beta$. & $\alpha_{\mathrm{I}}$. & A. $*$ & $\mathrm{~K}$ Atml $/ \mathrm{cm} \mathrm{2}^{2}$. \\
\hline Water $\left(100^{\circ} \mathrm{C}\right.$.) & $\ldots$ & $\ldots$ & $0.000047 ?$ & 0.00086 & $70 \cdot 8$ & 7,000 \\
\hline Ether $\ldots$ & $\ldots$ & $\ldots$ & O'000I II & 0.001513 & $38 \cdot 6$ & 3,860 \\
\hline Alcohol .... & $\ldots$ & $\ldots$ & 0.000083 & 0.00105 & $35^{\circ} 9$ & 3,590 \\
\hline Wood spirit & $\ldots$ & $\ldots$ & O.00009I & 0.00118 & 36.8 & 3,680 \\
\hline Chloroform & $\ldots$ & $\ldots$ & 0.000062 & o.0oII I & 50.8 & 5,080 \\
\hline Essence of terebentl & line & $\ldots$ & 0.000073 & 0.0007 & $27 \cdot 2$ & 2,720 \\
\hline Mercury $\quad \ldots$ & $\ldots$ & $\ldots$ & 0.0000035 & 0.00018 & $14 \cdot 6$ & I 4,600 \\
\hline Carbon bisulphide & $\ldots$ & $\ldots$ & 0.0000835 & 0.0012 & $40 \%$ & 4,070 \\
\hline
\end{tabular}

The results-with the exception of water, which is not really comparableagree moderately with those obtained by his first-quoted method. It may be noted that in a later paper + Dupré applies this second-quoted relation in a slightly altered form to determine $\mathrm{K}$ for the metals iron, copper, palladium, gold, and platinum. He further writes $\mathrm{K}$ or $\mathrm{A}$ in the form $\mathrm{A}=a \Delta^{2}$ where $\Delta$ is the density of the substance. + The term $a$ is analogous to the integral in Laplace's expression or to the term $a$ in van der Waal's equation, which appeared some years later (1873). The matter is not quite clear from Dupré's writings, but it certainly appears necessary to consider $a$ in Dupré's case as varying with temperature, for $\Delta$ varies with temperature, and Dupré assumed $\mathrm{K}$ itself to be independent of temperature. Apart from temperature considerations altogether, it is uncertain whether one can strictly apply either of Dupre's relations to the solid state, since crystalline form itself appears to be the outcome of forces which are absent in the liquid state, or at least do not possess the peculiar directive property necessary to the formation of crystals. It would seem, however, that if we are ever to know anything about the solid state it will be by some such extension of relationships which hold for the liquid state. In the present résumé, therefore, reference will be made to determinations of $\mathrm{K}$ for solids as well as for liquids-leaving the question of validity open.

\section{Values of $K$ from van der Waals Equation.}

In the well-known equation-

$$
\left(p+\frac{a}{v^{2}}\right)(v-b)=\mathrm{RT}
$$

the term $\frac{a}{v^{2}}$ is introduced to allow for cohesive forces, that is to say $\frac{a}{y^{2}}$ is the equivalent of $\mathrm{K}$. Van der Waals, in the $\mathrm{r} 88 \mathrm{I}$ edition of his book,

* $\mathrm{A}$ is simply $\mathrm{K}$ on Dupré's notation, and the numerical values are upon his system of units. In the last column I have added $\mathrm{K}$ (without recalculation $a b$ initio) in terms of atmospheres per $\mathrm{cm}^{2}$.

+ Ann. de Chim. et de Phys., 14, 87, 1868.

$\mp$ Dupré (loc. cit.) points out rather an interesting relation in connection with the metals mentioned, viz., the product of $a$ into the square of the chemical equivalent is constant. Dupré attempts to generalise this, but his method of treatment is questionable. 


\section{INTERNAL, MOLECULAR, OR INTRINSIC PRESSURE}

gives the following values for $\mathrm{K}$ in the case of several liquids at ordinary temperature. The numbers are regarded by the author as only approximate :-

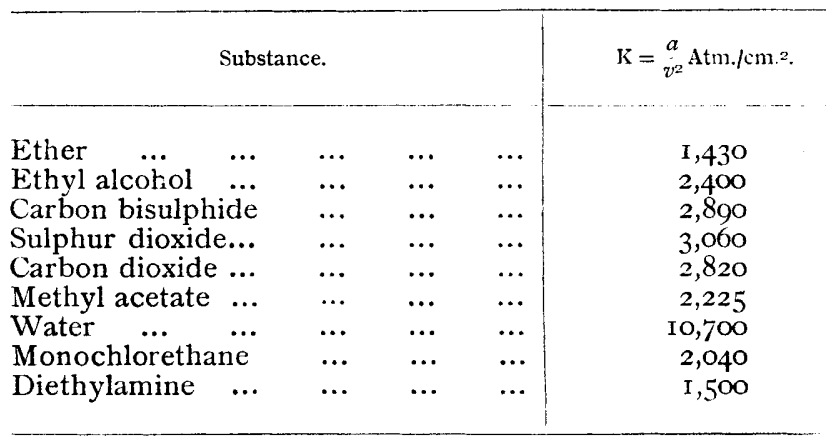

'The data on the next page, calculated on van der Waals' equation for $0^{\circ} \mathrm{C}$., are given by J. Traube.* The values for pentane are taken from a paper also by J. Traube. $\dagger$

Some of the results do not agree very well with Van der Waals' own calculations, but Traube claims his own to be based on more accurate data.

In this connection mention should be made of a paper by $\mathrm{P}$. Walden, + who gives a large quantity of data. His paper starts off, however, with what the writer considers an erroneous interpretation of Stefan's law, and the great bulk of the results are dependent on this initial step.

It will be observed that the figures, given for example by van der Waals, while of the same order of magnitude as Dupré's, are in all cases smaller, being indeed about one-half the values given by him. Van der Waals, it may be remarked, has always restricted the applicability of his equation to the liquid and gaseous states. Traube, however, $\S$ has applied it to the solid state as well, and in the table on pages 8 and 9 are given his values of $\mathrm{K}$ calculated as $\frac{a}{v^{2}}$. From the atomic weight $\mathrm{A}$ and the density $\delta$ Traube calculated the atomic volume $\frac{\mathrm{A}}{\delta}=v$ for temperature $t_{x}^{\circ}$ (generally $0^{\circ} \mathrm{C}$.), and from Fizean's values for the coefficient of expansion $a_{x} \|$ with temperature a second atomic volume was calculated. The values of $\alpha_{\mathrm{r}}$ hold for a mean temperature $t_{2}$. The value of $b$ and $v-b$ refer to the gram atom which, in the examples cited, Traube takes as being identical with the gram molecule. $a$ is given in litre-atmospheres (should be litre ${ }^{2}$ atmospheres), and $\mathrm{K}=\frac{a}{v^{2}}$ in atmospheres.

The last six substances given are taken from a table of $\mathrm{C}$. Benedicks.

An inspection of the values of $\mathrm{K}$ for solid substances shows that the numbers which are obtained are extraordinarily great-in fact, so great as

* Z. Physik. Ch., 68, 293, r9o9.

$\dagger$ Annalen d. Physik., 22, 540, 1907.

+ Z. Physik. Ch., 66, 385 , I909.

Z. anorg. $C h ., 34,4 \mathrm{I} 3$, I903.

Traube uses the symbol $3 \beta$ for the coefficient of expansion with temperature. In view of the fact that $\beta$ usually represents compressibility, it is more suitable, I think, to adopt the symbol $\alpha_{\mathrm{r}}$ in the above instance.

T Z. anorg. Ch. $47,459,1905$. 
INTERNAL, MOLECULAR, OR INTRINSIC PRESSURE 99

\begin{tabular}{|c|c|}
\hline 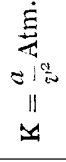 & 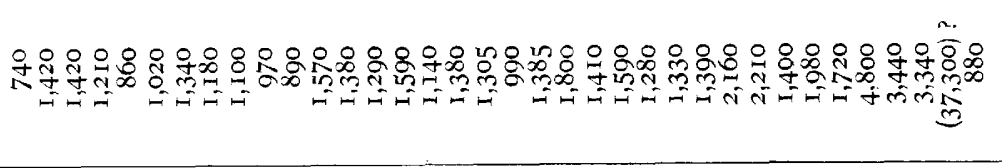 \\
\hline$=2$ & 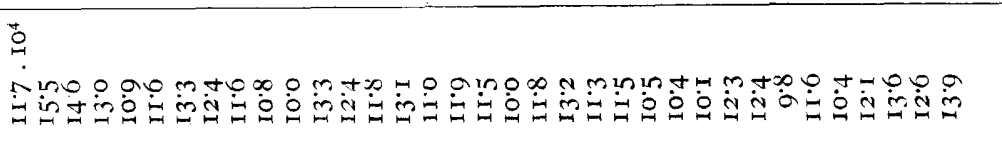 \\
\hline 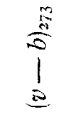 & 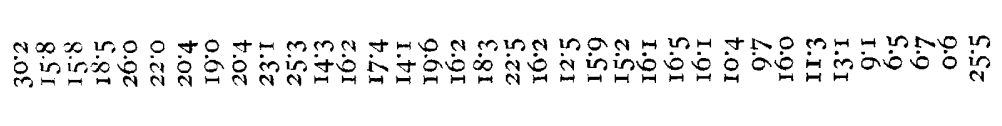 \\
\hline$\stackrel{20}{a^{2}}$ & 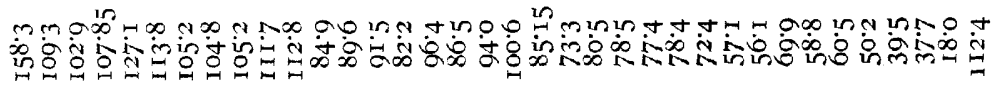 \\
\hline$=10$ & 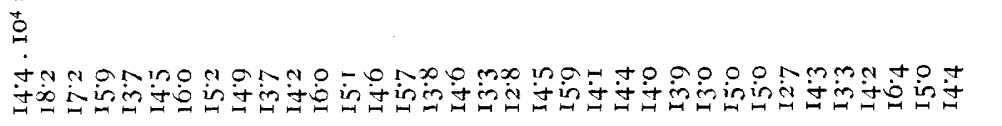 \\
\hline si & 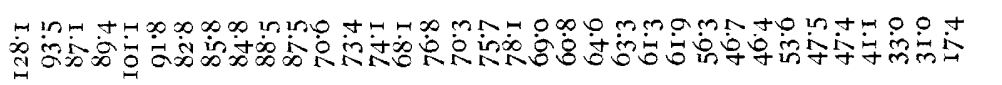 \\
\hline es & 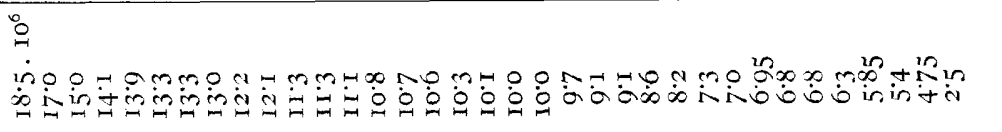 \\
\hline & 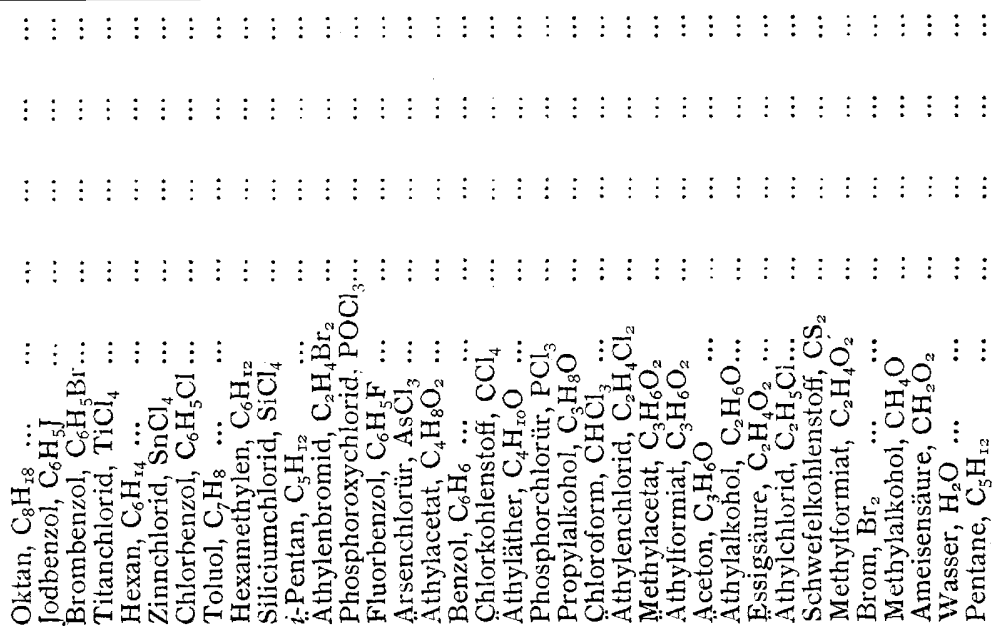 \\
\hline
\end{tabular}


IOO IN'TERNAL, MOLECULAR, OR INTRINSIC PRESSURE

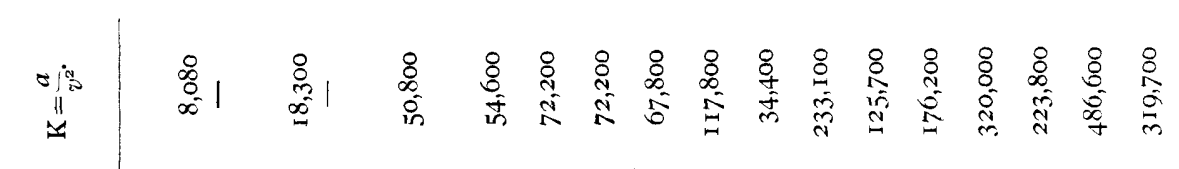

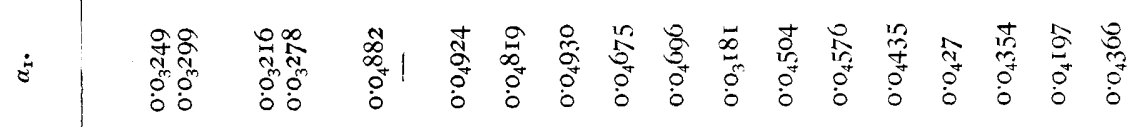

\begin{tabular}{|c|c|c|c|c|c|c|c|c|c|c|c|c|c|c|c|c|c|}
\hline$\dot{\Omega}$ & $\circ 8$ & $\circ:$ & ㅇ 1 & 웅 & ㅇ & $\circ$ & 요 & q & $\circ$ & 9 & & g & 0 & & & 0 & O \\
\hline
\end{tabular}

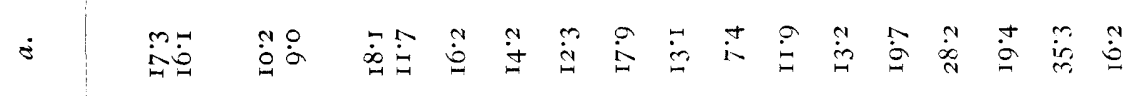

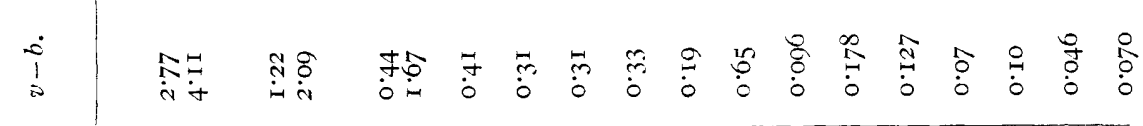

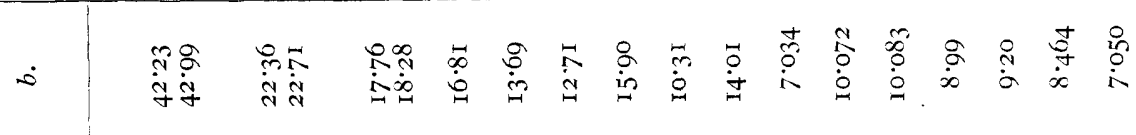

\begin{tabular}{|c|c|c|c|c|c|c|c|c|c|c|c|c|c|c|c|}
\hline $\begin{array}{ll}\ddot{2} \\
4 i \overrightarrow{0}\end{array}$ & 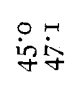 & 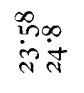 & $\begin{array}{l}\stackrel{2}{2} \\
\infty \\
\infty \\
0\end{array}$ & $\stackrel{\tilde{N}}{\stackrel{-}{-}}$ & $\begin{array}{l}8 \\
\stackrel{+}{+}\end{array}$ & $\begin{array}{l}0 \\
0 \\
\Leftrightarrow\end{array}$ & 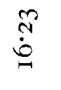 & $\begin{array}{l}0 \\
\text { in } \\
0\end{array}$ & $\begin{array}{l}\stackrel{8}{8} \\
\stackrel{+}{+}\end{array}$ & $\stackrel{\vec{i}}{\vec{i}}$ & 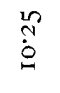 & 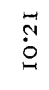 & $\begin{array}{l}8 \\
0 \\
0\end{array}$ & $\stackrel{\circ}{\sigma}$ & $\tilde{n}$ \\
\hline i- & ing & $\circ 8$ & $\stackrel{\sim}{\mathcal{N}^{2}}$ & 0 & 0 & 0 & \& & 0 & 0 & 0 & 0 & ते & $\stackrel{\sim}{\circ}$ & 0 & 0 \\
\hline
\end{tabular}

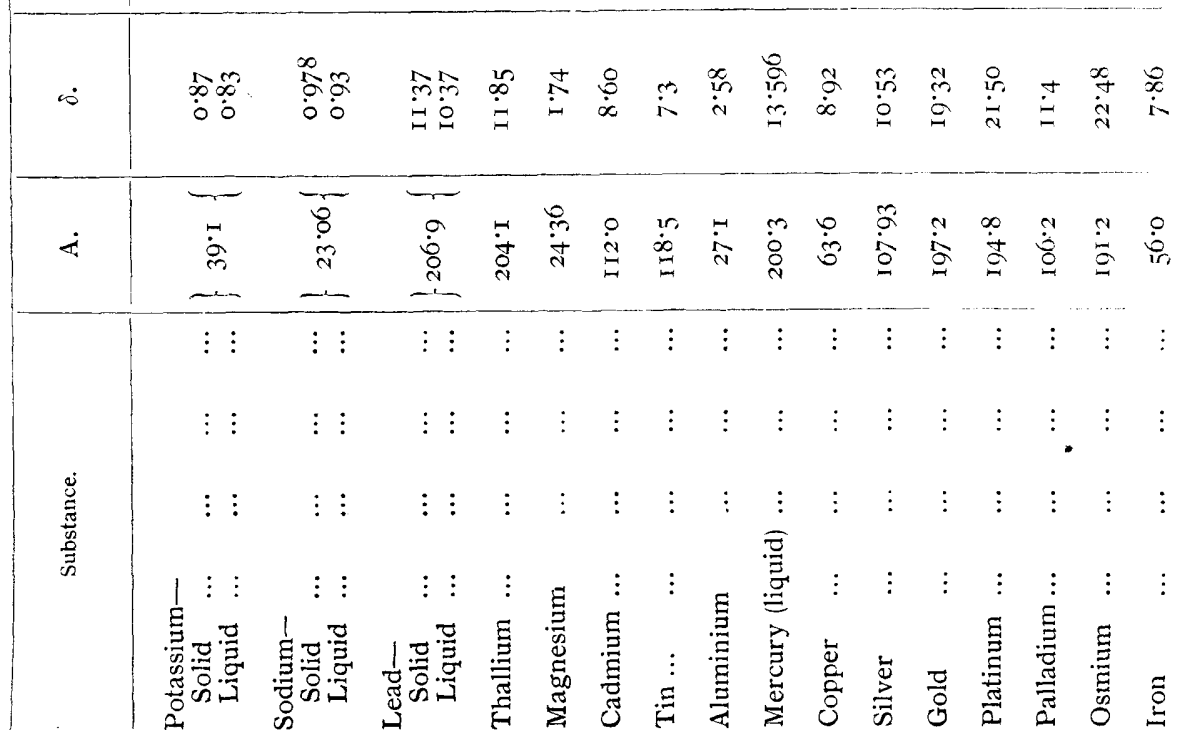




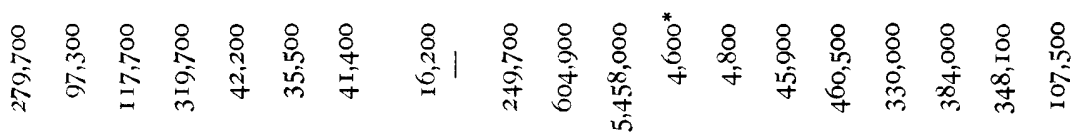

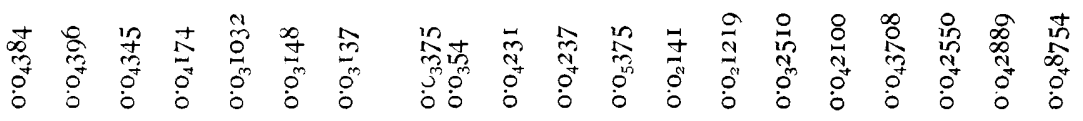

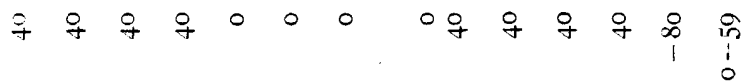

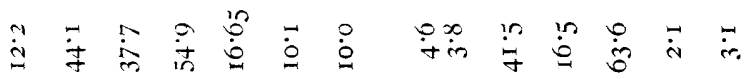

ஜ

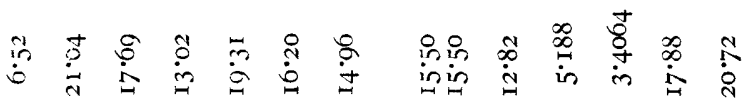

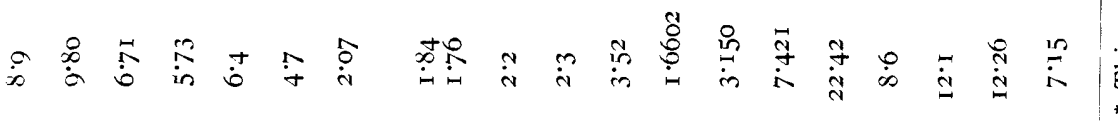

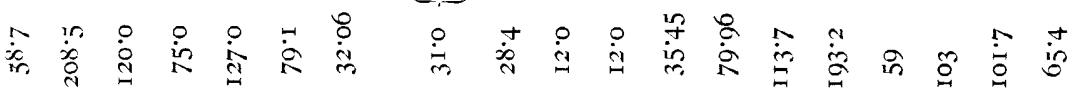

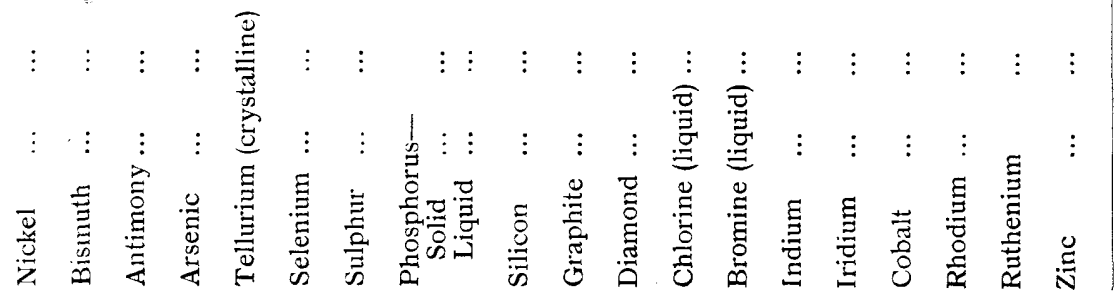


to be scarcely credible in many cases. We now pass on to consider the next expression for $\mathrm{K}$.

\section{An Approximate Formula for $K$ given by van der Waals.}

In the Dutch edition of his well-known work on the continuity of the liquid and gaseous states, p. 99, van der Waals (as quoted by Röntgen and Schneider *) deduces the expression-

where-

$$
\mathrm{K}^{2}=\frac{\mathrm{C}_{\mathrm{o}}(\mathrm{I}+\alpha t)}{v \beta},
$$

$\mathrm{C}_{\mathrm{o}}=$ volume of $\mathrm{I}$ gram molecule of vapour at $t_{\mathrm{n}}$ and $\mathrm{I}$ atm.

$v=$ volume of $\mathrm{I}$ gram molecule of liquid at $t_{0}$ and $\mathrm{I}$ atm.

$\alpha_{\mathrm{r}}=$ coefficient of gaseous expansion with temperature.

$\beta=$ coefficient of compressibility of liquid at constant temperature.

The above relation does not appear in the German edition nor in the English translation, so that it has probably been withdrawn by the author as not sufficientiy accurate. It may be of interest, however, to see just what it assumes. Starting with van der Waals' equation-

$$
p=\frac{\mathrm{R} \mathrm{T}}{v-b}-\frac{a}{v^{2}}
$$

we obtain on differentiating with respect to $z^{\prime}-$

$$
\frac{\partial p}{\partial v}=-\frac{\mathrm{RT}}{(v-b)^{2}}+\frac{2 a}{v^{3}} .
$$

Now if we neglect $\frac{2 a}{v^{3}}$ compared to $\frac{\mathrm{RT}}{(v-b)^{2}}$-for in the liquid state $b$ is very nearly equal to $v$ itself-we obtain-

$$
\frac{\partial v}{\partial p}=-\frac{(v-b)^{2}}{\mathrm{RT}}=-\frac{(v-b)^{2}}{(\mathrm{RT})^{2}} \mathrm{R}^{\prime} \mathrm{.}
$$

Now-

$$
\begin{aligned}
\mathrm{K} & =\frac{\mathrm{RT}}{v-b}, \text { neglecting } p, \\
\therefore \frac{\partial v}{\partial p} & =-\frac{\mathrm{RT}}{\mathrm{K}^{2}},
\end{aligned}
$$

or-

$$
\mathrm{K}^{2}=\frac{\mathrm{RT}}{\frac{\partial v}{\partial p}}=\frac{\mathrm{RT}}{v \beta}=\frac{\mathrm{C}_{\mathrm{o}}(\mathrm{I}+\alpha t)}{v^{\prime} \beta}
$$

provided we assume in the final step that RT may be approximately replaced by $\mathrm{C}_{\mathrm{o}}(\mathrm{I}+a t)$.

J. Traube $f$ tested this relation for a series of metallic elements-solid substances, to which, as already mentioned, van der Waals himself did not extend his equation. The results obtained by Traube are surprisingly good. Taking the metals to be monatomic, using the compressibility data of

*Wied. Ann., 29, 213, I886.

$\dagger$ Verhandlung d. deutsch. physik. Gesell., p. 23 I, I909. 
Richards and his pupils,* and calculating $\mathrm{K}$ or $\frac{a}{v^{2}}$ from the van der Waals equation (employing the coefficient of expansion data already given as well as that of Holborn and Day + ), Traube found that $\frac{a}{v^{2}} \sqrt{v \beta}$ is a fairly good constant, as it should be if the relation in question is valid. The results are given in the following table, in which the unit of pressure is that suggested by Richards, viz., the "megabar" $=0.987 \mathrm{~atm}$.

\begin{tabular}{|c|c|c|c|c|c|c|}
\hline \multicolumn{2}{|l|}{ Substance. } & $\begin{array}{c}\text { Atomic } \\
\text { Volume, } v .\end{array}$ & $\begin{array}{c}\text { Mean } \\
\text { Compressi- } \\
\text { bility, } \\
\beta \times 10^{6}\end{array}$ & $\begin{array}{c}\text { Atomic } \\
\text { Compressi- } \\
\text { bility. } \\
v \beta \times 10^{6}\end{array}$ & $\begin{array}{c}a \\
y^{2} \\
\text { Megabars. }\end{array}$ & $\frac{a}{v^{2}} \sqrt{ } v^{\prime} \beta \times 10^{-2}$ \\
\hline Nickel ... & $\cdots$ & $\begin{array}{l}\text { c.c. } \\
6 \cdot 7\end{array}$ & 0.27 & $I^{*} 74$ & 324,600 & $4 \cdot 28$ \\
\hline Platinum & $\cdots$ & $9^{\circ} \mathrm{I}$ & $0.2 \mathrm{I}$ & $I \cdot 9$ & $3^{24,200}$ & 448 \\
\hline Iron $\ldots$ & $\cdots$ & $7 \cdot 1$ & $0^{\circ} 40$ & $2 \cdot 84$ & 323,900 & $(5 \cdot 46)$ \\
\hline Palladium & $\ldots$ & $9 \cdot 3$ & 0.38 & $3 \cdot 53$ & 226,700 & $4 \cdot 26$ \\
\hline Copper... & ... & $7 \cdot 1$ & 0.54 & $3 \cdot 83$ & 236,100 & $4^{6} 62$ \\
\hline Gold $\quad \ldots$ & $\ldots$ & 10.2 & 0.47 & 479 & I 78,500 & $3^{\circ} 9 \mathrm{I}$ \\
\hline Silver $\quad .$. & ... & $10 * 3$ & 0.84 & 8.65 & I6I,900 & 476 \\
\hline Aluminium & $\ldots$ & $10^{\circ} \mathrm{I}$ & $r \cdot 3$ & 13.13 & I I 9,300 & 432 \\
\hline Zinc... & $\ldots$ & 95 & $1 \div 5$ & 1370 & 108,900 & 403 \\
\hline Cadmium & ... & I3.0 & $I^{\circ} 9$ & 2470 & 73,100 & 3.63 \\
\hline Tin $\quad \ldots$ & $\ldots$ & $I 6 \cdot 2$ & $I \cdot 6$ & $259^{\circ}$ & 68,700 & 349 \\
\hline Magnesium & .. & $13 \cdot 3$ & 27 & $359 \mathrm{I}$ & 73,100 & 438 \\
\hline Lead $\ldots$ & $\cdots$ & $18 \cdot 2$ & $2 \cdot 2$ & $40 \circ 04$ & $5 \mathrm{I}, 500$ & 3.26 \\
\hline Thallium & $\cdots$ & $17^{\circ} 2$ & $2 \cdot 6$ & $44^{\circ} 72$ & 55,300 & 370 \\
\hline Sodium... & $\ldots$ & 237 & I $5^{\circ} 4$ & $3^{6} 4^{\circ} 9^{8}$ & $x 8,500$ & 354 \\
\hline Potassium & $\ldots$ & $45^{\circ} 5$ & $3 \mathbf{I} \cdot 5$ & I $433 \cdot 25$ & 8,190 & 310 \\
\hline
\end{tabular}

The exceptional result in the case of iron is attributed by Traube to the presence of some carbon. Using the mean value for the constant, viz., 4.04, one finds $\mathrm{K}_{\mathrm{iron}}=239,000$ megabars.

The agreement obtained in the foregoing table is not, I think, to be taken as proof of the applicability of van der.Waals' equation to the solid state, but rather as justification for the approximations made in deducing the expression $\mathrm{K}_{2}=\frac{\mathrm{C}_{0}(\mathrm{I}+\alpha t)}{v \beta}$, viz., that $\frac{2 a}{v^{3}}$ is really negligible compared to $\frac{\mathrm{RT}}{(v-b)^{2}}$ at ordinary temperatures. Traube himself does not urge the quantitative significance of the above results, but considers them especially in relation to several other properties which he mentions as at least rendering probable the applicability of van der Waals' equation to the solid state. It may be noted with regard to van der Waals' equation in general (and any relation depending on it) that $\mathrm{K}$ is not assumed a constant independent of temperature, but that $\mathrm{K} / \delta^{2}$ is (where $\delta$ is the density of the substance). At least this is the case in the simplest form of van der Waals' equation.

\section{Bakker's Relation.}

This relation does not deal explicitly with $\mathrm{K}$ itself, but is so closely bound up with it as to necessitate a reference here. In $1888,+$ from considerations

* Z. Elektroch., I3, 519, I907.

+ Annalen d. Physik, 4, 104, I901.

+ Dissertation, Schiedam. 
somewhat similar to those of Dupré as regards the connection between cohesive forces and the latent heat of vaporisation, G. Bakker put forward the following relation-

$$
\lambda=\int_{v_{0}}^{v_{\mathrm{x}}} \mathrm{K} d v+p\left(v_{1}-v_{0}\right)
$$

where-

$\lambda=$ latent heat of vaporisation per gram.

$\left.\begin{array}{l}v_{1}=\text { volume of one gram of vapour } \\ v_{0}=\text { volume of one gram of liquid }\end{array}\right\}$ at the same temperature.

$p=$ vapour pressure.

We may write this expression in the approximate form-

$$
\lambda=\int_{\tilde{i}_{0}}^{v_{1}} \mathrm{~K} d v+\frac{\mathrm{RT}}{\mathrm{M}}
$$

or calling $\lambda_{i}$ the internal latent heat per gram-

$$
\lambda_{i}=\int_{v_{0}}^{v_{x}} \mathrm{~K} d v
$$

Bakker integrated this expression on the assumption that $\mathrm{K}$ may be represented as a function of $v$, according to the expression $\mathrm{K}=\frac{\mathrm{A}}{v^{2}}$, where $\mathrm{A}$ is a constant. One obtains by this means-

$$
\lambda_{i}=\mathrm{A}\left(\frac{\mathrm{I}}{v_{0}}-\frac{\mathrm{I}}{v_{1}}\right) \text {, or approximately } \frac{\mathrm{A}}{v_{0}} .
$$

It may be noted that Bakker deduced this expression without reference to van der Waals' equation. If we write $\mathrm{L}_{i}=$ the internal latent heat per unit volume of liquid-

$$
\mathrm{L}_{i}=\frac{\lambda_{i}}{v_{0}}=\frac{\mathrm{A}}{v_{0}^{2}}
$$

Now Duprés relation is $\mathrm{L}_{i}=\mathrm{K}$, so that combining Dupré's and Bakker's equations one obtains $\mathrm{K}=\frac{\mathrm{A}}{v_{0}^{2}}$. In van der Waals' equation, $\mathrm{K}=\frac{a}{v^{2}}$, so that the $\mathrm{A}$ in Bakker's equation would become identical with $a$ provided $\mathrm{K}$ were really represented by $\frac{a}{v^{2}}$, that is, provided " $a$ " were independent of temperature. Bakker himself* has shown the connection between $\mathrm{A}$ and $a$, viz., $\mathrm{A}=\left(a-\mathrm{T} \frac{\partial a}{\partial \mathrm{T}}\right)$. An important point must be noted in this connection. It is not sufficient to determine experimentally the value of $a$ which will fit van der Waals' equation at the temperature in question, and to use this found value for the integration of Bakker's expression-although the integration

* Z. physik. Ch., 12, 670, 1893 . 
is performed at constant temperature. The general thermodynamic relation for the phenomenon of vaporisation at constant temperature is-

$$
d \lambda_{i}=\left(\mathrm{T} \frac{\partial p}{\partial t}-p\right) d v
$$

where $p$ is the vapour pressure.

Suppose now that $a_{t}$ is the found value of $a$ at this temperature which satisfies the van der Waals equation for the homogeneous phase.

Then-

$$
p+\frac{a_{t}}{v^{2}}=\frac{\mathrm{RT}}{v-\bar{b}} \text {. }
$$

Hence-

$$
\mathrm{T} \frac{\partial p}{\partial t_{t}^{2}}=\frac{\mathrm{RT}}{v-b}-\frac{\mathrm{T}}{v^{2}} \frac{\partial a_{t}}{\partial t}
$$

or-

and therefore-

$$
\left(\mathrm{T} \frac{\partial p}{\partial t}-p\right)=p+\frac{a_{t}}{v^{2}}-p-\frac{\mathrm{T}}{v^{2}} \frac{\partial a_{t}}{\partial \mathrm{T}}
$$

$$
d \lambda_{i}=\frac{\mathrm{I}}{v^{2}}\left(a_{t}-\mathrm{T} \frac{\partial a_{t}}{\partial \mathrm{T}}\right)
$$

It is the expression $\left(a_{t}-\mathrm{T}_{\frac{\partial}{\partial \mathrm{T}}}\right)$ which we require for the integration of $\mathrm{K} d v$ - even assuming that $\mathrm{K}$ can be represented by a factor of some kind divided by $v^{2}$. Now it is known that $a$ decreases as temperature rises. That is $\frac{\partial}{\partial t}$ is negative and $\left(a-\mathrm{T} \frac{\partial a}{\partial \mathrm{T}}\right)>a$. One would expect therefore that the values for $\lambda_{i}$ calculated from the simplest form of Bakker's equation in which we use van der Waals' $a_{t}$ for A would be smaller than the observed values; and such is found to be the case. In fact, if we agree that Bakker's expression is correct in principle, we must assume that $\mathrm{T} \frac{a}{\partial \mathrm{T}}$ turns out to be a quantity of much the same magnitude as $a$ itself, so that $\left(a-\mathrm{T}_{\partial} \frac{\partial a}{\mathrm{~T}}\right)$ might be approximately written in general as $2 a$. The significance of this will be seen when we come later to examine an expression for $\lambda_{i}$ brought forward by Milner. To illustrate how far Bakker's relation in the form $\lambda=\frac{a_{t}}{v_{0}}+\frac{\mathrm{RT}}{\mathrm{M}}$ applies in practice, a table due to $\mathrm{J}$. Traube* is given below. It will be observed that $a_{K}$ (the value of van der Waals' constant at the critical tempcrature) is greater than $a_{t}$ (the value of the same "constant" at the temperature of vaporisation), and hence Traube gives two series of calculated values for the latent heat. The $a_{t}$ values were obtained by Traube from the van der Waals equation $\frac{a}{v^{2}}(v-b)=\mathrm{RT}$. Traube made use of the values of $b_{r}+$ obtained from the van der Waals equation at two slightly different temperatures in the region required. The values of $a_{\mathrm{K}}$ are those calculated by Guye f from the equation-

$$
a=\frac{27}{64} \frac{\mathrm{RT}_{\mathrm{K}}^{2}}{\mathrm{P}_{\mathrm{K}}}
$$

The column headed $\lambda$ calc. I. refers to $a_{\mathrm{K}} ; \lambda$ calc. II. refers to $a_{\mathrm{T}}$.

\footnotetext{
* Annalen d. Physik. [4] 8, 300, I902.

† Loc. cit., p. 284 ; ibid., 5, 552, 190 I.

+ Arch. Science phy's. et natur. Genèze, 9, 22, 1900.
} 


\begin{tabular}{|c|c|c|c|c|c|c|c|c|c|c|}
\hline \multicolumn{3}{|c|}{ Substance. } & $\mathrm{T}-273$ & $\begin{array}{c}b_{\mathrm{T}} \\
\text { in cc. }\end{array}$ & in $\begin{array}{c}y \\
\mathrm{cc}\end{array}$ & $\begin{array}{c}a_{\mathrm{K}} \\
\text { in } \\
\text { litre }{ }^{2} \mathrm{~atm} .\end{array}$ & $\begin{array}{c}a_{\mathrm{T}} \\
\text { in } \\
\text { litre }^{2} \text { atm. }\end{array}$ & $\stackrel{\lambda}{\text { calc. I }}$ & $\begin{array}{c}\lambda \\
\text { calc. II. }\end{array}$ & $\begin{array}{c}\lambda \text { observed. } \\
\text { in } \\
\text { cals./gram- } \\
\text { molecule. }\end{array}$ \\
\hline Mercury & $\cdots$ & $\cdots$ & $360 \cdot 0$ & $14 \cdot 2$ & 1572 & - & $8 \cdot 68$ & - & 14,660 & $14.540^{*}$ \\
\hline Isopentane ... & $\cdots$ & $\ldots$ & $28 \cdot 0$ & $87 \cdot 3$ & $117^{\circ} 9$ & $18 \cdot 20$ & II'23 & 4,340 & 2,910 & 6,000 \\
\hline$n$. Hexane ... & $\cdots$ & $\ldots$ & $60 \%$ & $I 04^{\circ} \mathrm{I}$ & 1398 & $245^{8}$ & 15.37 & - & 3,340 & - \\
\hline n. Heptane... & $\cdots$ & $\ldots$ & 98.4 & 1194 & 1625 & 30.85 & 18.69 & - & 3,530 & - \\
\hline$n$. Octane $\ldots$ & $\cdots$ & $\cdots$ & 125.8 & $135^{\circ} 0^{\circ}$ & $186^{\circ} 9$ & $36 \cdot 58$ & $22 \cdot 17$ & 5,540 & 3.680 & 8,090 \\
\hline Decane $\quad .$. & $\cdots$ & $\cdots$ & I $59^{\circ} 6$ & - & $23 I^{\prime} 3$ & $48 \cdot 59$ & - & 5,955 & 一 & 8,540 \\
\hline Ethyl ether & $\cdots$ & $\ldots$ & $34 \cdot 8$ & $79^{\prime} 3$ & $106 \% 4$ & I $7 \% 44$ & 10.56 & 4,590 & 3,020 & 6,260 \\
\hline Ethyl chloride & $\cdots$ & $\ldots$ & 120 & - & $71 \cdot 2$ & I I 22 & - & 4,390 & - & 6,160 \\
\hline Chloroform & $\because$ & $\ldots$ & $60 \% 9$ & - & 845 & 1471 & - & 4,880 & $\longrightarrow$ & 6,985 \\
\hline Carbon tetrachlor & ide & $\ldots$ & $76 * 2$ & $78 \cdot 1$ & 1037 & 1920 & 12.04 & 5,185 & 3,510 & 7,130 \\
\hline Stannic chloride & $\cdots$ & $\ldots$ & I I $2: 5$ & $97 \cdot 2$ & $13 I \cdot I$ & $26 \cdot 94$ & 16.05 & 5,750 & 3,740 & 7,950 \\
\hline Carbon bisulphide & & $\ldots$ & $46 \cdot 2$ & - & $62 \cdot 1$ & I I' 20 & - & 5,010 & 一 & 6,600 \\
\hline Diethylamine & $\cdots$ & $\ldots$ & $5^{8 \cdot 0}$ & - & $\operatorname{Iog} 4$ & I7'O & - & 4,430 & 一 & 6,650 \\
\hline Benzene $\quad \ldots$ & $\cdots$ & $\ldots$ & $80 \cdot 25$ & $72 \cdot 1$ & $96 \cdot 2$ & $18 \cdot 36$ & II'I 3 & 5.050 & 3.510 & 7,290 \\
\hline Fluorbenzene & $\cdots$ & $\ldots$ & $85 \cdot 1$ & $76 \cdot 7$ & IOI'9 & 19.95 & 12.11 & 5,500 & 3,600 & 7,600 \\
\hline Chlorobenzene & ... & $\ldots$ & $132 \%$ & $86 \cdot 3$ & 1143 & 25.54 & $155 \mathrm{I}$ & - & 4,100 & 8,100 \\
\hline Toluene $\quad \ldots$ & ... & $\ldots$ & 110.8 & - & II $8: 3$ & $24 \cdot 08$ & - & 5.700 & - & 7,690 \\
\hline$m$. Xylene ... & $\cdots$ & $\cdots$ & $139^{\circ} 9$ & - & $140^{\circ} 0$ & $30 \cdot 39$ & - & 6,090 & - & 8,300 \\
\hline Ethyl benzene & $\cdots$ & $\cdots$ & I34.7 & 一 & I $39^{\circ} 3$ & $28 \cdot 63$ & - & 5,795 & 一 & 8,110 \\
\hline Propyl benzene & $\ldots$ & $\ldots$ & $157^{\circ} 2$ & - & $162 \cdot 2$ & $35^{\circ} 89$ & - & 0,220 & - & 8,620 \\
\hline Cymol $\quad \ldots$ & $\cdots$ & $\ldots$ & $175^{\circ} \mathrm{O}$ & $\rightarrow$ & I 849 & $42 \cdot 20$ & - & $6,43^{\circ}$ & 一 & 8.900 \\
\hline Methyl formace & $\cdots$ & $\ldots$ & $32 \cdot 9$ & $47 \cdot 6$ & 627 & II 38 & 6.54 & 5.010 & 3,140 & 6,970 \\
\hline Ethyl formate & $\ldots$ & $\ldots$ & $54^{\circ} \circ$ & -1 & 847 & I5.68 & - & 5,140 & - & $7,35^{\circ}$ \\
\hline Ethyl acetate & $\ldots$ & $\ldots$ & 759 & $78 \cdot 7$ & 1060 & 2047 & I I 79 & $5 \cdot 380$ & 3,390 & 7,640 \\
\hline Methyl propionat & & $\cdots$ & $80^{\circ} 0$ & $76^{\circ} 4$ & Iof 6 & $20 \cdot 24$ & II'24 & 5400 & 3,300 & 7,420 \\
\hline Ethyl propionate & $\cdots$ & $\cdots$ & 9877 & - & I $28 \cdot I$ & 2555 & 一 & 5,580 & - & 7,870 \\
\hline Methyl isobutyrat & & $\ldots$ & $92 \cdot 5$ & 一 & $126+7$ & 2452 & 一 & 5,420 & 一 & 7,710 \\
\hline Ammonia ... & ... & $\ldots$ & $-38 \cdot 5$ & - & $29^{\circ} 2$ & 401 & - & 3,800 & - & 5,600 \\
\hline $\begin{array}{l}\text { Oxygen (containi } \\
\text { cent. nitrogen) }\end{array}$ & ing & & -1830 & - & $28 \cdot 2$ & $\times 33$ & - & 1,320 & - & 1,620 \\
\hline Nitrogen $\ldots$ & $\cdots$ & $\cdots$ & -1944 & 一 & $33^{2} 2$ & $\begin{array}{l}\mathbf{5 3} \\
\mathbf{I} \cdot 35\end{array}$ & - & I, 140 & - & 1,620 \\
\hline Sulphur dioxide & $\cdots$ & $\ldots$ & Io. & - & $43^{\circ} 9$ & 6.61 & - & 4,175 & - & 6,000 \\
\hline Methyl alcohol & $\ldots$ & $\ldots$ & 645 & $32: 8$ & $42 \cdot 8$ & 953 & 5.08 & 6.070 & 3.550 & 8,570 \\
\hline Ethyl alcohol & $\cdots$ & $\ldots$ & $78 \cdot 1$ & - & $62 \cdot 3$ & 15.22 & - & 6,620 & & 9,440 \\
\hline Acetic acid ... & $\cdots$ & $\cdots$ & 119.2 & $48 \cdot 0$ & $63 \cdot 8$ & $17 \cdot 60$ & 8.29 & 5.390 & 3.930 & $7,47^{\circ}$ \\
\hline Water & $\ldots$ & $\cdots$ & 100 & 155 & 18.9 & 577 & 3.29 & 8,190 & 4,980 & 9,660 \\
\hline
\end{tabular}

It will be observed that the agreement between observed and calculated values is not very good, and rather remarkably the discrepancy is greater in the case of the $a_{t}$ values than in the case of those calculated from the $a_{\mathrm{K}}$ values. Traube discusses these discrepancies, but it would be outside our present purpose to follow him further. It may be noted that in the case of mercury the value of $\lambda$ calculated from $a_{t}$ agrees well with the observed value, thus pointing to the possibility that in the case of this substance the constant $a$ is in reality very nearly independent of temperature. The same is approximately true for bromine given in a later paper by Traube, $f$ viz. $: \lambda$ observed 7,296 cals., calculated 6,620 cals. The same thing seems to hold good for zinc and cadmium (and perhaps for other metals as well), viz. :-

\begin{tabular}{|c|c|c|c|}
\hline & & $\begin{array}{l}\lambda \text { observed per } \\
\text { Molecule. }\end{array}$ & $\frac{a_{t}}{\tau^{\prime}}+\mathrm{RT} \cdot+$ \\
\hline Zinc $\quad \ldots$ & $\ldots$ & 25,500 & $25,45^{\circ}$ \\
\hline Cadmium & $\cdots$ & 23,480 & $23,45^{\circ}$ \\
\hline
\end{tabular}

For sulphur, however, the discrepancy is marked : $\lambda$ observed 23,170 cals. per

* This is not the figure given by Traube in 1902, but the later value given by him in the $Z$. anorg. Ch., 34, 423, 1903 .

$\dagger Z$. anorg. $C h$., 34 .

$\ddagger$ Traube, Z. anors. Ch., loc. cit. 
gram-molecule, $\frac{a_{t}}{v}+\mathrm{RT}=32,300$ cals. Traube $*$ calculates $a_{t}$ for a series of metals and non-metals and then, applying Bakker's equation, calculates the corresponding latent heats of vaporisation-but these cannot be compared with observed values, since the latter have not yet been determined.

It may be noted that in Traube's table of liquid substances already given, water and the alcohols which are known to be considerably associated do not appear to behave in any characteristic manner different from other liquids as regards the values of $\lambda$ calculated and $\lambda$ observed. This is rather surprising.

\section{Milner's Equation.}

In view of the discrepancies between calculated and observed values to which we have drawn attention in dealing with the Bakker equation, and the possible explanation on the ground that $a$ varies with temperature, it is interesting to consider an equation put forward by Milner + which deals with the same problem of vaporisation, but which, while bearing a superficial resemblance to Bakker's formula, is in reality fundamentally different. Bakker's initial step consists in writing-

$$
\lambda_{i}=\int_{v_{0}}^{v_{\mathrm{I}}} \mathrm{K} d v
$$

Milner, on the other hand, makes use of the inverse integral, viz.-

$$
\lambda_{i}=\int_{\mathrm{K}}^{0} v d \mathrm{~K}
$$

The mechanism of the process (of vaporisation) suggested by Milner in support of this latter expression is not clear to me. So far as I know the strongest evidence in its favour lies in a consideration of the analogy which may exist between the equilibrium of a liquid in contact with vapour and the equilibrium of a reversible (metallic) electrode dipping into a solution containing a salt of the metal. In calculating the potential difference in such a case it was formerly considered that the "osmotic" work term could be represented as $\int_{\mathrm{P}}^{\pi} \mathrm{P} d v$, where $\mathrm{P}$ stands for osmotic pressure of the ions in the solution and $\pi$, the upper limit of the integral, refers to the "solution pressure" of the metal. Such an expression, if one assumes the perfect gas laws, gives, as is well known, extravagant values for $\pi$. This question has been taken up by Milner himself, $\ddagger$ and especially by Lehfeldt, $\S$ and the question of osmotic pressure in general by A. W. Porter.\| The difficulty hinges on carrying out an imaginary cycle which shall be really reversible. To allow ions to go direct from the electrode at a pressure $\pi$ to the solution at osmotic pressure $P$ is an irreversible process, and any work (less than in the reversible process) may be got from it. If we consider the simplest case of a reversible step,

* Z. anorg. Ch., loc. cit.

+ Phil. Mag. [5], 43, 296, I897.

Ibid. [5], 49, 4I7, I900.

Ibid. [5], 48, 430, I899; ibid., 38I, 190I.

if Proc. R. Soc., A, 79, 519, I907; ibid., A, 80, 457, I908; 手ourn. Physic. Ch., I2, $404,1908$. 


\section{Io8 INTERNAL, MOLECULAR, OR INTRINSIC PRESSURE}

namely, the transference of a gram-molecule of solvent at vapour pressure $p_{0}$ to solution at vapour pressure $p_{\text {, }}$, we find that the carrying out of such a process involves three stages, i.e., three external work terms. First, the required quantity of solvent is vaporised at constant pressure $p_{0}$, the external work being $p_{0} v_{0}$. This quantity is now isolated from the bulk, and is further expanded to volume $v_{x}$, the pressure simultaneously changing to $p_{1}$. The external work done is $\int_{z_{0}^{\prime}}^{v_{I}} p d v$. Finally, the mass is pressed by means of the piston into the solution, the work done being $-p_{1} v_{1}$. On integrating by parts the expression for the work of the second stage, it is found that we are left simply with the expression $\int v d p$ as the maximum external work for the whole step. Of course, if the system is such that the gas laws hold, it is immaterial, as far as the numerical result is concerned, whether we integrate $p d v$ or $v d p$. When the system is such that the gas laws are far from holding good, the result is obviously no longer the same. Lehfeldt has shown this very strikingly in the case of the solution pressure of zinc, in making use of van der Waals' formula instead of $\mathrm{P} v=\mathrm{RT}$. The expression $\int v d p$ is, however, reached above, independent of whether gas laws hold or not. In the electrical case it seems extremely difficult to imagine the cycle, and in the case of vaporisation no reversible mechanism involving internal work and energy changes has as yet been suggested. The point which must be noted is that in writing $\int v d \mathrm{~K}$ as the total internal work term involved in the step of passing from liquid to vapour we are really looking upon internal pressure and external pressure as the same sort of thing as far as thermodynamic considerations are concerned. The fact is, the question is very obscure, and the analogy of writing $\int v d \mathrm{~K}$ in the one case because we find $\int v d p$ in other cases is not a very rigid one. If, however, we do start out with the expression -

$$
\lambda_{i}=\int v d \mathrm{~K}
$$

we find on integration, assuming $\mathrm{K}=\frac{a}{v^{2}}$, that-

$$
\lambda_{i}=2 a\left(\frac{\mathrm{I}}{v_{\mathrm{o}}}-\frac{\mathrm{I}}{v_{\mathrm{I}}}\right),
$$

i.e., a result just twice as great as that obtained by Bakker's equation. It will be seen on comparison of the values given in the previous table of liquids that if we double the $\lambda$ calculated on $a_{t}$ we obtain very good agreement indeed between observed and calculated values. This in itself, however, is not sufficient to afford justification of Milner's formula as against Bakker's. The few results, e.g., for mercury, cadmium, and zinc, would now become rather inexplicable exceptions; and further, the agreement obtained in the other cases would point to $a_{t}$ being independent of temperature, which is not the case.

One of the chief difficulties in this problem is whether van der Waals' equation (or indeed any equation of state) is applicable to the transition from 


\section{INTERNAL, MOLECULAR, OR INTRINSIC PRESSURE IO9}

liquid to vapour. If we consider the actual state of things as they exist, the relation between $p$ and $v$ is given by the curve-

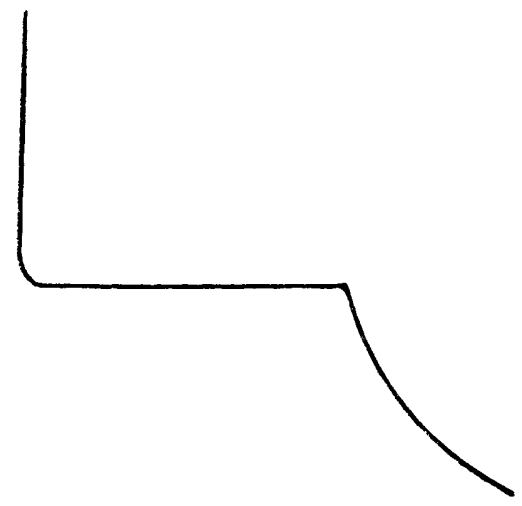

in which the vapour pressure $p$ remains constant throughout a certain distance. Van der Waals' equation, of course, does not give this curve at all, and if we use the equation (to make possible the integration either of $\mathrm{K} d v$ or $v d \mathrm{~K}$ ) we thereby assume that the curve has the following shape-

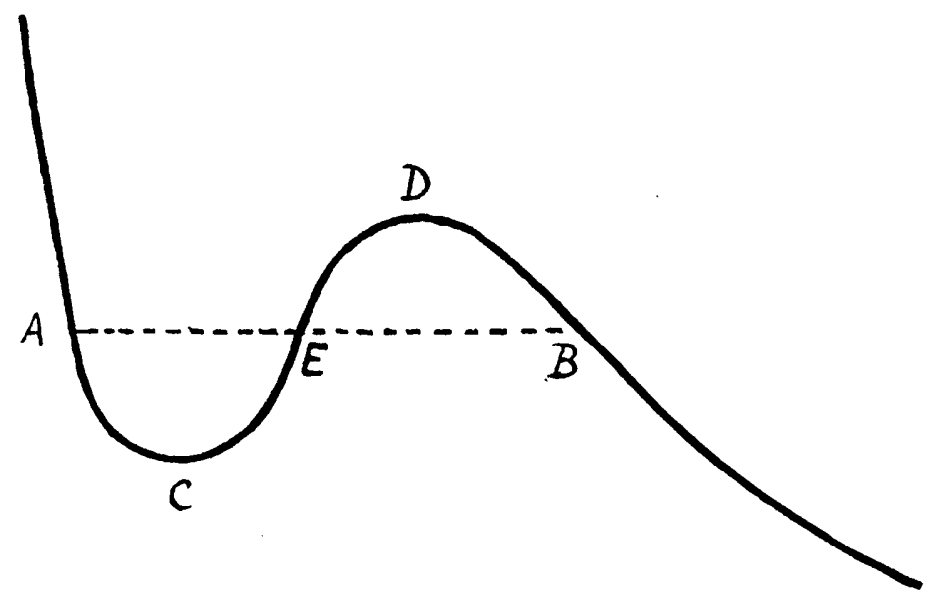

in which $p$ does not remain constant during the transition from liquid to vapour. In this case $\int v d p$ is not zero unless the two areas AEC and BDE are equal (Maxwell, I875). Since in practice we have never yet reached the points $\mathrm{D}$ or $\mathrm{C}$, and therefore have no experimental evidence for the shape of the curve DC, we cannot regard Maxwell's theorem as rigorously proved. At the same time we must regard it as an exceedingly likely assumption.

To return to Milner's expression. Let us write--

$$
\lambda_{i}=\int v d \theta
$$

where $\theta$ is the thermal pressure and is given by $\theta=p+\mathrm{K}$. Then-

$$
\int v d \theta=\int v\left(d p+d\left(\frac{a}{v^{2}}\right)\right)=\int v d p-\int \frac{2 a}{\tau^{2}} d v
$$


Assuming Maxwell's theorem $\int v d p=o$,

$$
\therefore \lambda_{i}=\int_{v_{0}}^{v_{\mathrm{x}}} \frac{2 a}{v^{2}} d v=2 a\left(\frac{\mathrm{I}}{v_{0}^{\prime}}-\frac{\mathrm{I}}{v_{1}}\right),
$$

this being Milner's final expression, which is thus seen to contain implicitly Maxwell's assumption.

The introduction of the coefficient 2 into the expression for the latent heat is of interest in connection with Dupré's values for $\mathrm{K}$ already discussed. It will be remembered that Dupré puts $\mathrm{K}=\mathrm{L}_{i}=\frac{\lambda_{i}}{v_{0}}$. Putting in the value $\frac{2 a}{v_{0}}$ for $\lambda_{i}$ from Milner's equation, one obtains $\mathrm{K}=\frac{2 a}{v_{0}^{2}}$, while van der Waals' assumption is that $\mathrm{K}=\frac{a}{v_{0}^{2}}$. On Dupré's and Milner's assumptions, therefore, one may expect values of $\mathrm{K}$ twice as great as those obtained from van der Waals' equation. This is shown to be the case approximately in the following :-

\begin{tabular}{|c|c|c|c|c|}
\hline \multicolumn{3}{|l|}{ Substance. } & K Atm. (Dupré). & K Atu. (van der Traals). \\
\hline Water ... & $\ldots$ & $\ldots$ & 23,900 & $10,500-11,000$ \\
\hline Ether $\ldots$ & $\ldots$ & $\ldots$ & 2,426 & $I, 300-1,430$ \\
\hline Ethyl alcohol ... & $\ldots$ & $\ldots$ & 7,266 & $2, \mathrm{IOO}-2,400$ \\
\hline Carbon bisulphide & $\ldots$ & $\ldots$ & 4,704 & $2,890-2,900$ \\
\hline
\end{tabular}

It is to be remembered, however, in the first place, that Dupré considered $\mathrm{K}$ itself constant ; thence $a$ must be a variable, so that Dupré's equations are not compatible with van der Waals', and secondly, the coefficient 2 might after all be in Bakker's relation (provided we knew $\left(a-\mathrm{T} \frac{\partial a}{\partial \mathrm{T}}\right)$ instead of simply $a$ ), so that the comparison of the $\mathrm{K}$ values does not speak absolutely in favour of Milner's expression.

On reviewing the question as a whole, perhaps the safest course at present is to regard the expression-

$$
\lambda_{i}=\frac{2 a}{i_{0}}
$$

as a useful semi-empiric relation, which holds well for substances whose molecules are polyatomic.

\section{Milner's Second Relation.}

Milner* has deduced another expression for the latent heat of vaporisation from kinetic considerations. The expression, which involves the van der Waals $b$ instead of $a$, is-

$$
\begin{gathered}
\lambda_{i}=\frac{\mathrm{RT}}{\mathrm{M}}\left(\log \frac{v_{\mathrm{s}}-b}{v_{0}-b}+\frac{b}{v_{0}^{\prime}-b}-\frac{b}{v_{\mathrm{x}}-b}\right) ; \\
\quad \text { Plit. Mag., loc. cit. }
\end{gathered}
$$


$v_{0}$ and $v_{1}$ refer, as before, to the liquid and vapour states respectively. Milner also deduces the expression from the more general form of van der Waals' equation, in which no assumption is made as to the special form of $\mathrm{K}$, viz.-

$$
\mathrm{K}(v-b)=\frac{\mathrm{R} T}{\mathrm{M}}
$$

Since the final expression does not contain $\mathrm{K}$ or $a$, it is rather beyond our present purpose to discuss it further. It is noteworthy, however, that the expression given in Nernst's text-book* only contains the first term of Milner's equation, viz.-

$$
\lambda_{i}=\frac{\mathrm{RT}}{\mathrm{M}} \log \frac{v_{1}-b}{v_{0}-b}
$$

the terms $\left(\frac{b}{v_{0}-b}-\frac{b}{v_{1}-b}\right)$ being omitted. Nernst refers to a deduction

of the abbreviated form by Kammerlingh Onnes. $t$ In the examples given by Nernst the calculated value for $\lambda$ is considerably less than the observed. From an equation given by Milner, ${ }_{+}^{+}$it seems that the Nernst-Onnes expression is approximately half that of Milner. Again we have the question of a coefficient 2 coming in. It certainly does seem in favour of the correctness of Milner's views that both of his equations agree in giving approximately the same values for $\lambda_{i}$, these being double those of Bakker or Onnes. Traube $\S$ has examined the Nernst-Onnes expression, and shows that on applying it to ten typical non-associated liquids, the theoretical value is approximately two-thirds of the observed. For a further discussion of Milner's equation, cf. C. Dieterici,\| who regards it as substantially correct.

\section{Richards's Formula.}

Th. W. Richards $\uparrow$ has suggested the relation-

$$
\mathrm{K}=\mathrm{C} \frac{\partial t}{\partial v}
$$

This was obtained by considering that the heat $\mathrm{C} d t$ which has to be added to a small element of the liquid, volume $d v$, was equal to the internal work done, $\mathrm{K} d v$. Richards applied his equation to the case of several elementary substances given in the following table. (The values of $\mathrm{K}$ were given in the first instance by Richards in megadynes. The figures here given are those recalculated by J. Traube, $* * *$ using $\mathrm{I}$ atm. as the unit. I have also included for comparison Traube's values of $\mathbf{K}$, obtained simply by applying the van der Waals equation to the substances in question.)

With the exception of carbon in the form of diamond, Traube's and Richards's results are proportional to one another, but that is about all. Richards's results are so extraordinarily high as to be quite incredible. His

* Theorct. Chemic, 6th ed., pp. 24I, 242, 1909.

$\dagger$ Archives Níerlandaises, 30, I0I, I897.

† Loc. cit., p. 304.

$\$$ Annalen d.Physik., 5, 555, I90 I.

II Ibid., 66, 826, I 898 .

- Z. physik. Ch., 40, 176, I902.

** Z. anorg. Ch., 34, 416, 1903 . 


\begin{tabular}{|c|c|c|c|c|c|c|}
\hline \multicolumn{4}{|c|}{ Substance. } & K Atm. (Richards). & K Atm. (Traube). & Ratio. \\
\hline Sodium & $\ldots$ & ... & $\ldots$ & 53,000 & I 8,300 & 29 \\
\hline Lead $\ldots$ & $\ldots$ & $\ldots$ & $\ldots$ & r 59,900 & 50,800 & $3 \cdot 1$ \\
\hline Mercury & $\cdots$ & $\ldots$ & $\ldots$ & 104,600 & 34,400 & $3^{\circ} \mathrm{O}$ \\
\hline Copper & $\ldots$ & $\ldots$ & $\ldots$ & 663,300 & 233,100 & $2 \cdot 9$ \\
\hline Magnesium & $\ldots$ & $\ldots$ & $\ldots$ & 221,100 & 72,200 & $3 \cdot I$ \\
\hline Cadmium & $\ldots$ & $\ldots$ & $\ldots$ & $2 \mathrm{II}, 200$ & 72,200 & $2^{\circ} 9$ \\
\hline Silicon ... & $\cdots$ & $\cdots$ & $\cdots$ & 745,300 & 249,700 & $3^{\circ} \mathrm{O}$ \\
\hline $\mathrm{C}$ (diamond) & $\ldots$ & $\ldots$ & $\ldots$ & $4,837,000$ & $5,45^{8,000}$ & {$[0 \cdot 89]$} \\
\hline
\end{tabular}

equation assumes $\mathrm{K}$ to be independent of temperature and still more independent of volume. This latter assumption is quite invalid.

Traube's Formula.

As a result of the comparison of the values already given of $\mathrm{K}$ obtained from Richards's formula and those from the van der Waals equation, Traube suggests the empiric relation-

$$
\mathrm{K}=\frac{1}{3} \mathrm{C} \frac{\partial t}{\partial v}
$$

This need not, however, be discussed further.

\section{Benedicks's Formula.}

In the course of an investigation * as to whether van der Waals' equation may be applied to the solid state, in which it is pointed out that Traube's considerations are not conclusive, C. Benedicks has deduced the following expression for $\mathrm{K}$ -

$$
\mathrm{K}=\frac{a}{v^{2}}=\frac{\mathrm{R}}{v}\left(\frac{\mathrm{I}}{3 \beta}+2 \mathrm{~T}\right)=\text { approximately } \frac{\mathrm{R}}{v_{3} \beta}=\frac{\mathrm{R}}{v a_{\mathrm{r}}} .
$$

Writing $\alpha_{1}$ for $3 \beta$, which on Benedicks's notation stands for the coefficient of expansion of the liquid with temperature, $v$ denotes volume in the liquid state. Since the expression is based on van der Waals' equation it embodies the assumptions underlying this equation. Benedicks's formula is probably the most convenient one for the purpose of calculating $K$ (assuming van der Waals' equation). It will be seen on comparing this relation with that of Richards that they would be identical if $\mathrm{C}$ (say the atomic or molecular heat) were identical with $\mathrm{R}$ (the gas constant per gram-molecule). From. this standpoint the invalidity of Richards's relation becomes apparent.

It will have been observed that all the expressions for internal, intrinsic, or molecular pressure hitherto put forward rest on one or other of the assumptions, viz., (I) that $\mathrm{K}$ itself is independent of temperature, (2) that $\mathrm{K}$ may be written $\frac{a}{v_{0}^{2}}$, and that $a$ (and $b$ ) in van der Waals' equation are independent of temperature, i.e., that $\mathrm{K} / \delta^{2}$ is independent of temperature.

Neither of these assumptions is justifiable, though undoubtedly that of van der Waals is much nearer the truth. 
Apparently the only accurate relation * is the general thermodynamic one--

$$
\mathrm{K}-\mathrm{L}_{i}=\mathrm{T}\left(\frac{\partial \mathrm{K}}{\partial \mathrm{T}}\right)_{v}
$$

but this does not allow us to go further unless some new assumption be made with respect to $\mathrm{K}$ and $\mathrm{T}$. The problem therefore resolves itself into one closely analogous to that which has been investigated for some time past by Nernst. Some new assumption with respect to $\mathrm{K}$ or with respect to $\frac{\partial \mathrm{K}}{\partial \mathrm{T}}$ must be put forward, but so far none is forthcoming. In the absence of anything better I would therefore tentatively suggest as a working hypothesis that the fractional change in $\mathrm{K}$ per degree is the same as the fractional change in $L_{i}$ per degree. That is to say that-

$$
\frac{\mathrm{I}}{\mathrm{K}} \frac{\partial \mathrm{K}}{\partial \mathrm{T}}=\frac{\mathrm{I}}{\mathrm{L}_{\mathrm{x}}} \frac{\partial \mathrm{L}_{\mathrm{r}}}{\partial \mathrm{T}} \text {. }
$$

It must be remembered that this assumption is quite an arbitrary one. My object in suggesting it is rather to call attention to the necessity of an assumption of some kind than to insist upon the correctness of the present one.

Continuing, we find-

$$
T \frac{\partial K}{\partial T}=\frac{T K}{L_{r}} \frac{\partial L_{x}}{\partial T}
$$

and-

$$
\mathrm{K}-\mathrm{L}_{i}=\frac{\mathrm{TK}}{\mathrm{L}_{\mathrm{r}}} \frac{\partial \mathrm{L}_{\mathrm{r}}}{\partial \mathrm{T}}
$$

hence-

$$
\mathrm{K}=\frac{\mathrm{L}_{i}}{\mathrm{I}-\frac{\mathrm{T}}{\mathrm{L}_{\mathrm{r}}} \frac{\partial \mathrm{L}_{\mathrm{r}}}{\partial \mathrm{T}}}
$$

If $L_{i}$ had no temperature coefficient $\mathrm{K}$ would be identical with $\mathrm{L}_{i}$ (Dupré's relation).

The above expression may be illustrated by a few examples.

Take the case of ether at ordinary temperatures. From the data of Ramsay and Young, at $0^{\circ}$ C.-

At $10^{\circ} \mathrm{C}$ -

$$
\begin{gathered}
\lambda=93^{\circ} 27 \text { cals./gram; } \frac{\mathrm{RT}}{\mathrm{M}}={ }^{\circ} 0^{\circ} 92 \text { cals. } ; \therefore \lambda_{i}=82^{\circ} 35 \text { cals. } \\
\delta_{\infty^{\circ}}=0^{\circ} 73^{62} ; \therefore \mathrm{L}_{i^{\circ} \mathrm{C}} \mathrm{C}=60^{\circ} 626 \text { cals. } / \mathrm{c} . \mathrm{c} .
\end{gathered}
$$

$$
\begin{gathered}
\lambda=90 \cdot 77 \text { cals. } ; \frac{\mathrm{RT}}{\mathrm{M}}=\mathrm{Ir} \cdot 32 \text { cals. } ; \lambda_{i}=79^{\circ} 45 \text { cals. } \\
\delta_{10^{\circ}}=0.7245 ; \therefore \mathrm{L}_{i_{10^{\circ} \mathrm{C}} \mathrm{c}=57^{\circ} 5^{6} \text { cals. } / \text { c.c. }} \\
\therefore \frac{\partial \mathrm{L}_{i}}{\partial \mathrm{T}}=-0^{\circ} 3066 \text { cals. } / \text { c.c. degree. }
\end{gathered}
$$

For the temperature $o^{\circ} \mathrm{C}-$

$$
\begin{gathered}
\frac{\mathrm{T}}{\mathrm{L}_{\mathrm{I}}} \frac{\partial \mathrm{L}_{\mathrm{r}}}{\partial \mathrm{T}}=-\frac{0.3066 \times 273}{60 \cdot 626}=-\mathrm{r} \cdot 37 . \\
\therefore\left(\mathrm{I}-\frac{\mathrm{T}}{\mathrm{L}_{\mathrm{r}}} \frac{\partial \mathrm{L}_{\mathrm{r}}}{\partial \mathrm{T}}\right)=(\mathrm{I}-(-\mathrm{I} \cdot 37))=2 \cdot 37 .
\end{gathered}
$$

* Assuming that internal work and internal energy can be treated with respect to one another in the same way as external work and internal energy.

VOL. VII-T5 


\section{II4 INTERNAL, MOLECULAR, OR INTRINSIC PRESSURE}

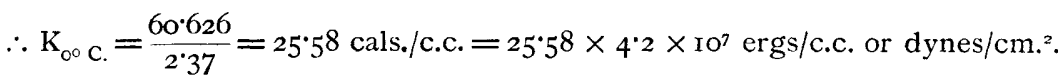
$=\mathrm{I}, 074 \mathrm{~atm}$. per $\mathrm{cm} .^{2}$.

Van der Waals' equation gives . . . I,300-I,430 atm.

Dupré $\left(\mathrm{K}=\mathrm{L}_{i}\right)$ gives. . . . . . $2,426 \mathrm{~atm}$.

The agreement with Van der Waals' expression is thus fairly good.

Ethyl Alcohol at $0^{\circ} \mathrm{C}$.-From the data of Ramsay and Young, at $\mathrm{o}^{\circ} \mathrm{C}$.-

$\lambda=220^{\circ} 9$ cals. $; \frac{\mathrm{RT}}{\mathrm{M}}=\mathrm{Ir} \cdot 87$ cals. $; \therefore \lambda_{i}=209^{\circ} 03$ cals.

$$
\delta_{0}=0.8002 ; \therefore \mathrm{L}_{i}=167 \cdot 26 \text {. }
$$

At $\mathrm{IO}^{\circ} \mathrm{C}$ - -

$$
\begin{aligned}
& \lambda=22 \mathrm{I}^{\circ} 2 \text { cals. } ; \frac{\mathrm{RT}}{\mathrm{M}}=\mathrm{I} 2^{\circ} 3 \text { cals. } ; \therefore \lambda_{i}=208 \cdot 9 \text { cals. } \\
& i_{100}=079916 ; \therefore L_{i}={ }^{6} 653^{6} 6 . \\
& \therefore \frac{\partial \mathrm{L}_{\mathrm{r}}}{\partial \mathrm{T}}=-0^{\circ} \mathrm{I} 9 \text {. } \\
& \frac{\mathrm{T}}{\mathrm{L}_{x}} \frac{\partial \mathrm{L}_{1}}{\partial \mathrm{T}}=-\frac{273 \times 0^{\circ} \mathrm{I9}}{\mathrm{I} 67^{\circ} 26}=-0^{\circ} 3 \mathrm{I} \text {. } \\
& \therefore \mathrm{K}=\frac{\mathrm{I} 67^{\circ} 26}{\mathrm{I} \cdot 3 \mathrm{I}}=\mathrm{I} 27^{\circ} 6 \mathrm{cals} . \mathrm{c.c.} \\
& =5,359 \mathrm{~atm} \text {. }
\end{aligned}
$$

Van der Waals' equation gives . . . 2,100-2,400 atm. Dupré's relation gives . . . . 7,266 atm.

Carbon Disulphide at $\mathrm{O}^{\circ}$ C. - At $\mathrm{O}^{\circ} \mathrm{C}$. (Winkelmann)-

$$
\begin{gathered}
\lambda=89^{\circ} 5 \text { cals. } ; \frac{\mathrm{RT}}{\mathrm{M}}=7 \cdot 2 ; \therefore \lambda_{i}=82 \cdot 3 \text { cals. } \\
\delta_{0^{\circ}}=\mathrm{I} \cdot 2937 ; \therefore \mathrm{L}_{i}=106 \cdot 47 \mathrm{cals} .
\end{gathered}
$$

At $\mathrm{IO}^{\circ} \mathrm{C}$ -

$$
\begin{aligned}
& \lambda=88{ }^{\circ} 74 \text { cals. } ; \frac{\mathrm{R}^{\prime} \mathrm{T}}{\mathrm{M}}=7{ }^{\circ} 44 ; \therefore \lambda_{i}=8 \mathrm{r}_{3} \cdot \text {. } \\
& \delta_{10^{\circ}}=\mathrm{I} \cdot 2786 ; \therefore \mathrm{L}_{i}=103 \cdot 95 \text {. } \\
& \therefore \frac{\partial \mathrm{L}_{i}}{\partial \mathrm{T}}=-0.25^{2} \text {. } \\
& \frac{T}{L_{x}} \frac{\partial L_{r}}{\partial T}=-0.646 \text {. } \\
& \therefore \mathrm{K}=\frac{\mathrm{ro6} \cdot 47}{\mathrm{r} \cdot 646}=64.7 \mathrm{cals} . / \mathrm{c} . \mathrm{c} \text {. } \\
& =2,717 \mathrm{~atm} \text {. }
\end{aligned}
$$

Van der Waals' equation gives . . . 2,890 atm.

Dupré's equation gives . . . . 4,704 atm. 


\section{INTERNAL, MOLECULAR, OR INTRINSIC PRESSURE II5}

I should like to emphasise again that the above examples are worked out on the basis of an assumption which at the present stage, at any rate, is quite empiric in nature. The whole point is that if we are ever to get to know internal pressure accurately, some further assumption in addition to those already made is a necessity.

In conclusion I gladly take this opportunity of expressing my thanks to Professor A. W. Porter, of this College, for the kindness with which he has offered helpful criticism on several of the various relationships which have been brought up in this Paper. As a particular instance I am indebted to him for the demonstration that Milner's equation (the first one quoted) involves the Maxwell assumption regarding the areas on the $p v$ diagram for liquid-vapour mixtures. 